\title{
Short communication: The effects of cabergoline administration at dry-off of lactating cows on udder engorgement, milk leakages, and lying behavior
}

\author{
A. Bach, ${ }^{*}{ }^{1}$ A. De-Prado, $\ddagger$ and A. Aris $\dagger$ \\ *ICREA (Institució Catalana de Recerca i Estudis Avançats), 08010 Barcelona, Spain \\ †Department of Ruminant Production, IRTA (Institut de Recerca i Tecnologia Agroalimentàries), 08140 Caldes de Montbui, Spain \\ $\ddagger$ †eva Santé Animale, 33500 Libourne, France
}

\section{ABSTRACT}

Cabergoline is an ergot derivative with high affinity for the $\mathrm{D}_{2}$ dopamine receptors whose dopaminergic effects cause inhibition of prolactin (PRL) secretion; thus, it could be considered a molecule that acts as a potential dry-off facilitator. One hundred ninety-nine Holstein cows (102 primiparous; 97 multiparous) producing $\geq 18 \mathrm{~kg} / \mathrm{d}$ at dry-off were split in 2 treatments to evaluate the effects of diminishing PRL secretion at dry-off (between 70 and $50 \mathrm{~d}$ from the expecting calving date) on udder engorgement, milk leakage, and cow well-being after dry-off. Treatments consisted of a single i.m. injection of $5 \mathrm{~mL}$ of a solution containing $5.6 \mathrm{mg}$ of cabergoline (CAB; Velactis, Ceva Santé Animal, Libourne, France) or $5 \mathrm{~mL}$ of saline solution as a placebo (CTRL). Each animal was evaluated for presence or absence of milk leakages during the $4 \mathrm{~d}$ following dry-off and udder engorgement was determined using a digital algometer. Lying behavior was recorded during $10 \mathrm{~d}$ after dry-off. Twenty-five cows from each treatment were randomly chosen and blood sampled at 3 and $15 \mathrm{~d}$ after dry-off, and again at 5 and $3 \mathrm{~d}$ before the expected calving date to determine serum PRL concentrations. Cows on CAB had lower serum PRL concentrations than cows on CTRL at 3 and $15 \mathrm{~d}$ after dry-off. Average udder engorgement was lower for cows on CAB than for cows on CTRL following dry-off, and it decreased as days after dry-off increased. The overall incidence of milk leakage in cows on CAB $(3.1 \pm 0.88 \%)$ was $73.5 \%$ of that obtained in cows on CTRL (11.7 \pm $1.64 \%$ ); cows on $\mathrm{CAB}$ had 0.2 lower odds of incurring milk leakage than cows on CTRL. The day following dry-off, CAB cows lied about $1.5 \mathrm{~h} / \mathrm{d}$ more than cows on CTRL. We conclude that i.m. administration of 5.6 mg of cabergoline at dry-off effectively reduces PRL

\footnotetext{
Received April 26, 2015.

Accepted June 17, 2015.

${ }^{1}$ Corresponding author: alex.bach@icrea.cat
}

secretion, udder engorgement, and milk leakages, and improves lying time the day following dry-off.

Key words: involution, mammary gland, prolactin

\section{Short Communication}

With increasing milk production, drying off has become a challenging period for dairy cows. In fact, it is not difficult to find cows producing more than 30 $\mathrm{kg} / \mathrm{d}$ at dry-off. During this period, the cow is highly susceptible to new IMI (Eberhart, 1986), and this risk is thought to increase as the level of milk production at dry-off increases (Rajala-Schultz et al., 2005) because the gland continues to temporally produce milk, which accumulates in the udder and may lead to leakages (Klaas et al., 2005). Furthermore, accumulation of milk at dry-off may lead to discomfort and pain (O'Driscoll et al., 2011), and it has been postulated that increased udder pressure between milkings may alter lying time and patterns of dairy cows (Österman and Redbo, 2001). However, little information is available about changes in lying patterns of dairy cows around dry-off. One study (Leitner et al., 2007) reported that cows receiving a treatment that reduced milk production at dry-off had longer lying bouts during the $7 \mathrm{~d}$ following dry-off compared with control cows.

A potential method to facilitate dry-off would consist of inducing a direct cessation of milk production by interfering with hormonal signals. For instance, intramammary infusions of CN hydrolysate have been shown to reduce milk secretion in dairy cows (Leitner et al., 2007; Ponchon et al., 2014). Also, blocking the release of prolactin (PRL) by binding dopamine $\mathrm{D}_{2}$ receptors using quinagolide has been shown to decrease milk production in both early- (Lacasse et al., 2011) and late-lactation (Ollier et al., 2013) cows and to hasten the involution of the mammary gland at dry-off (Ollier et al., 2014). A similar strategy would consist of administering cabergoline at dry-off. Cabergoline is an ergot derivative with high affinity for $\mathrm{D}_{2}$ dopamine receptors, which cause inhibition of PRL secretion (Romagnoli et 
al., 2009). In nonruminant animals, cabergoline has a much longer half-life $(\sim 70 \mathrm{~h})$ than quinagolide $(17 \mathrm{~h})$, and it also has less adverse effects than quinagolide (Kasum et al., 2014). However, in cattle, half-life of cabergoline has been reported to be $\sim 20 \mathrm{~h}$ (Velactis; European Medicines Agency, 2014). The hypothesis behind the current study was that the use of cabergoline would cease milk synthesis, resulting in a reduction in udder engorgement and milk leakages and an improvement in the well-being of the cow that would be evident through increased lying times and longer lying bouts after dry-off. Thus, the objectives of our study were to evaluate responses of high-yielding cows treated with cabergoline at dry-off versus untreated cows on udder engorgement, milk leakages, and cow well-being.

One hundred ninety-nine female Holstein cows (102 primiparous; 97 multiparous) were enrolled in this study. Animals were housed in a commercial farm in north-central Spain (SAT La Travesía, Cortes, Spain). All procedures were approved and supervised by the Animal Care Committee of IRTA. All cows were fed once daily (ad libitum) until dry-off time when they were abruptly changed to a dry-cow ration and moved from freestall pens to bedded packs. While lactating, cows were milked in a rotary parlor 3 times a day at 0600, 1400, and $2200 \mathrm{~h}$. The study followed a complete randomized block design. Randomization was performed using a computerized random generation number for each block. Block was the week of enrollment (cows were dried on Tuesdays). For a cow to be included in our study, she had to be free of mastitis, between 70 and $50 \mathrm{~d}$ before the expecting calving date, and producing an average of $\geq 18 \mathrm{~kg} / \mathrm{d}$ for the last 3 d before drying-off. All cows were dried-off abruptly. At drying time (right after the last milking), 99 cows received an i.m. injection of $5 \mathrm{~mL}$ of a solution containing $5.6 \mathrm{mg}$ of cabergoline (CAB; Velactis, Ceva Santé Animal, Libourne, France) and the remaining 100 cows received an i.m. injection of $5 \mathrm{~mL}$ of the same excipient used in $\mathrm{CAB}$ as a placebo (CTRL). After the last milking, each quarter was infused with $7 \mathrm{~mL}$ of a solution containing $0.6 \mathrm{~g}$ of cloxacillin benzathine (Orbenin Extra, Zoetis, Madrid, Spain).

After drying, cows were brought back to the milking parlor at $1100 \mathrm{~h}$ (at a different time than when they were typically milked), with all the equipment (except the rotary table) turned-off and thus without the noise of the vacuum pumps, pulsators, and so on; then, each animal was evaluated for presence or absence of milk leakages during the $4 \mathrm{~d}$ following drying-off. Milk leakage was defined as milk dropping or flowing from the teat. During this time, udder engorgement was also determined using a digital algometer (Commander, JTech Medical Industries, Midvale, UT) that was modified by welding a 2-cm washer at $2 \mathrm{~cm}$ from the tip of the algometer. The measure consisted of applying force to the caudo-ventral side of the rear left and right half udders using the modified algometer, and to stop applying force when the skin of the udder made contact with the washer. The repeatability of the measures obtained by the modified algometer was tested in a pretrial study that involved 20 lactating cows. Udder firmness of each cow was measured using the modified algometer described above for 5 consecutive days on the caudo-ventral side of the rear right and left udders $30 \mathrm{~min}$ before and $30 \mathrm{~min}$ after milking. Udder pressure before and after milking was $43.5 \pm 1.17$ and $20.6 \pm$ $0.66 \mathrm{~kg} \cdot \mathrm{m} / \mathrm{s}^{2}$ (mean $\pm \mathrm{SD}$ ), respectively, with 100 and $95 \%$ of the values falling within 2 and 1.2 standard deviations above and below the average, respectively. Therefore, the repeatability of this technique was considered acceptable under the criterion of British Standards Institution (BSI, 1975), that sustains that $95 \%$ of values should be within the range of 2 standard deviations above and below the average.

At dry-off, all cows were equipped with a HOBO Pendant G Acceleration Data Loggers (Onset Computer Corporation, Bourne, MA) on the right hind leg using cohesive bandages to record total daily lying time on an individual basis at 1-min intervals to estimate number and duration of lying bouts and total daily lying time (Ledgerwood et al., 2010). Lastly, 25 cows from each treatment were randomly chosen and blood sampled from the tail vein at dry-off at 3 and $15 \mathrm{~d}$ after dry-off, and again at 5 and $3 \mathrm{~d}$ before the expected calving date. These samples were subsequently analyzed for serum PRL concentrations using a bovine ELISA kit (Cusabio, Hubei, China) with intra- and interassay coefficients of variation of $<15 \%$.

Milk leakage was treated as a binary response variable and analyzed using a mixed-effects logistic regression model, including the random effect of cow and the fixed effects of treatment, parity, and days relative to dry-off, plus their interactions. Milk production at dryoff entered the model as a covariate. Udder engorgement, lying behavior, and blood data were analyzed using a linear mixed-effects model with the same fixed effects described above. In both models, day entered the analysis as a repeated measure.

Average milk production at dry-off did not differ $(P$ $=0.91$ ) between treatment groups, and it was $24.5 \pm$ 0.37 and $24.5 \pm 0.38$ for cows on CTRL and CAB, respectively (the lowest value for both groups was 18.0 $\mathrm{kg} / \mathrm{d}$, and the greatest value was 35.0 and $34.0 \mathrm{~kg} / \mathrm{d}$ for CTRL and CAB cows, respectively). Also, length of the dry period did not differ $(P=0.76)$ between treatments, and it was $58.7 \pm 0.70$ and $58.8 \pm 0.70 \mathrm{~d}$ for CTRL and CAB cows, respectively (the lowest value 
was 33 and $37 \mathrm{~d}$, and the longest value was 71 and 70 $\mathrm{d}$, for CTRL and CAB cows, respectively).

As expected, cows on $\mathrm{CAB}$ had lower $(P<0.05)$ serum PRL concentrations $(22.2 \pm 2.08 \mathrm{ng} / \mathrm{mL})$ than cows on CTRL $(27.9 \mathrm{ng} / \mathrm{mL})$, which proves that blocking dopamine $\mathrm{D}_{2}$ receptors with cabergoline effectively reduced PRL production by the pituitary gland. The reduction in serum PRL concentration obtained herein with a single dose of cabergoline $(5.6 \mathrm{mg} / \mathrm{cow})$ was lower than the decrease in serum PRL in studies that applied $4 \mathrm{mg} / \mathrm{d}$ of quinagolide from $\mathrm{d}-4$ to 3 relative to dry-off (Ollier et al., 2013, 2014). As shown in Figure 1, the difference in serum PRL concentrations was mainly due to a lower $(P<0.05)$ serum PRL concentrations at d 3 and 15 after dry-off in CAB than in CTRL cows. It is interesting to note that $15 \mathrm{~d}$ after dry-off, serum PRL concentrations were still lower $(P<0.05)$ in $\mathrm{CAB}$ than in CTRL cows. The half-life of cabergoline has been reported to be about $70 \mathrm{~h}$ (Kasum et al., 2014) in dogs and mice and about $20 \mathrm{~h}$ in cattle (Velactis SPC Mexico; C646.2.03.E.0). The results herein showed a sustained decrease in serum PRL concentrations 15 $\mathrm{d}$ after injection, in line with studies in other species showing a persistent effect of cabergoline on serum PRL concentration (Ferrari et al., 1986; Mattei et al., 1988).

Udder engorgement decreased $(P<0.05)$ as days since dry-off increased (Figure 2). Overall, average udder engorgement was lower $(P<0.01)$ in $\mathrm{CAB}(44.8 \pm$ $\left.0.66 \mathrm{~kg} \cdot \mathrm{m} / \mathrm{s}^{2}\right)$ than in CTRL cows $(48.0 \pm 0.66 \mathrm{~kg} \cdot \mathrm{m} /$ $\mathrm{s}^{2}$ ) mainly due to a greater udder pressure at $\mathrm{d} 1$ after dry-off in CTRL $\left(50.2 \pm 0.66 \mathrm{~kg} \cdot \mathrm{m} / \mathrm{s}^{2}\right)$ compared with CAB $\left(43.0 \pm 0.66 \mathrm{~kg} \cdot \mathrm{m} / \mathrm{s}^{2}\right)$ cows. Interestingly, udder engorgement at d 1 after dry-off was lower $(P<0.05)$ in CAB than in CTRL cows, but apparently the effects of CAB decayed on d 2 after dry-off, and udder engorgement of $\mathrm{CAB}$ cows increased to similar values of those found in CTRL cows. No differences in udder engorgement were noted between primiparous (46.2 \pm $\left.0.62 \mathrm{~kg} \cdot \mathrm{m} / \mathrm{s}^{2}\right)$ and multiparous $\left(46.8 \pm 0.66 \mathrm{~kg} \cdot \mathrm{m} / \mathrm{s}^{2}\right)$ cows, and no interaction was observed between parity and treatment on udder engorgement.

Milk leakage was evaluated in the milking parlor, and although all the equipment was turned-off and cows were brought to the milking area at different times than when they typically milked, this may have increased the incidence of milk leakage for both treatment groups. Nevertheless, the overall incidence of milk leakage in cows on CAB $(3.1 \pm 0.88 \%)$ was $73.5 \%$ of that obtained in cows on CTRL $(11.7 \pm 1.64 \%)$; and cows on $\mathrm{CAB}$ had 0.2 lower $(P<0.001)$ odds $(95 \% \mathrm{CI}=0.09-0.46)$ to incur in milk leakage than cows on CTRL. These data support the hypothesis that the reduction in PRL due to the stimulation of dopamine $\mathrm{D}_{2}$ receptors effectively ceases milk synthesis. The greatest $(P<0.05)$ difference in the incidence of milk leakage between $\mathrm{CAB}$ and CTRL cows was for d 1 and 2 after dry-off. The difference for $\mathrm{d} 1$ after dry-off was dramatic, as no cow in the CAB treatment showed milk leakage. Parity had also an effect $(P<0.05)$ on milk leakage, with multiparous cows being 1.94 times $(95 \% \mathrm{CI}=0.92-4.10)$ more $(P$

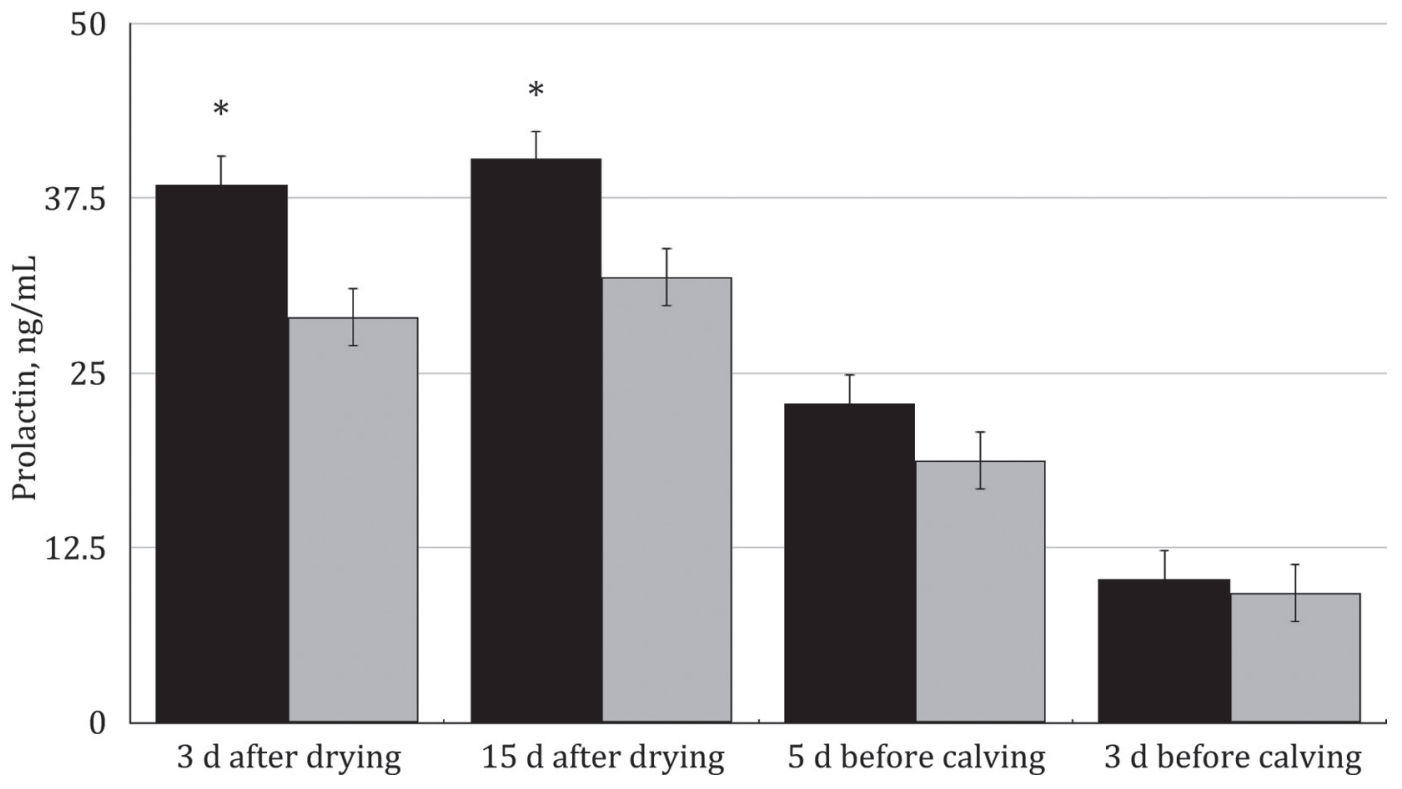

Figure 1. Serum prolactin concentration $(\mathrm{ng} / \mathrm{mL})$ of cows treated with a placebo (CTRL; black bars) and cows treated with cabergoline (CAB; gray bars) at dry-off. Error bars depict SEM at each time point. Asterisks denote time points when values for CTRL and CAB cows differ at $P<0.05$. 


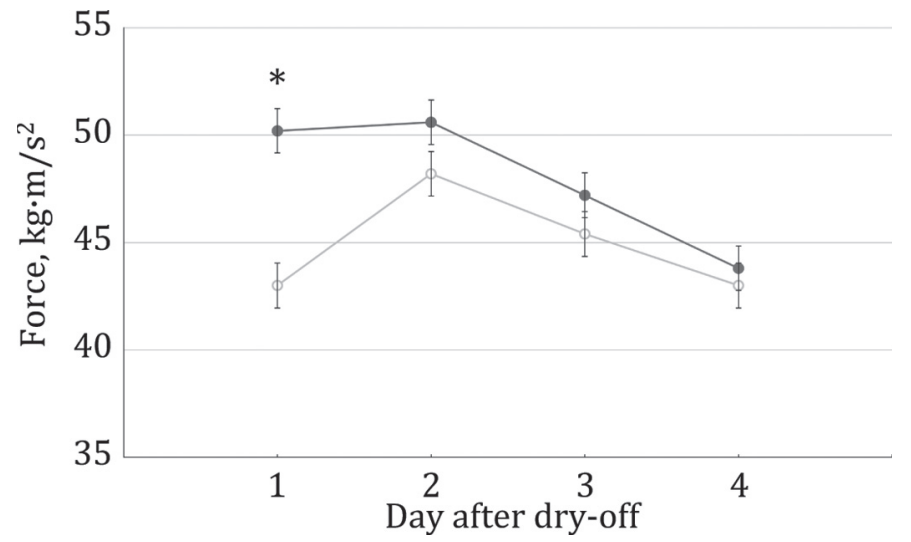

Figure 2. Udder engorgement (estimated by measuring the force needed to be applied to the udder using a modified algometer; see Materials and Methods for description) as affected by treatment [closed circles correspond to cows treated with a placebo (CTRL); open circles correspond to cows treated with cabergoline (CAB) at dry-off] and days since dry-off. Error bars depict SEM at each time point. Asterisk denotes the time point when values for CTRL and CAB cows differ at $P<0.05$.

$<0.005)$ likely to suffer milk leakage $(10.0 \pm 1.5 \%)$ than primiparous cows $(5.7 \pm 1.2 \%)$ independent of the treatment received. There is little information in the literature about milk leakage and parity, but Klaas et al. (2005) reported no difference in the incidence of milk leakage between primiparous and multiparous cows.

Lying time (min/d) following dry-off was not affected by parity $(P=0.66)$ or level of milk production at dryoff $(P=0.65)$. Similarly, no interaction was observed between treatment and parity on lying time $(P=0.61)$. Overall, lying time was not affected by treatment alone $(P=0.31)$ either; however, an interaction $(P<0.001)$ occurred between treatment and days after dry-off. The day following dry-off, CTRL cows lied about $1.5 \mathrm{~h} / \mathrm{d}$ less $(679 \pm 10.9 \mathrm{~min} / \mathrm{d})$ than cows on $\mathrm{CAB}(773 \pm 10.9$ $\mathrm{min} / \mathrm{d}$ ). Tucker et al. (2009) reported a lower lying time after dry-off in cows producing $\sim 9$ versus cows producing $\sim 6 \mathrm{~kg} / \mathrm{d}$ at dry-off. The difference in resting time between CTRL and CAB cows could be associated with the greater udder engorgement on CTRL cows than on $\mathrm{CAB}$, which probably caused discomfort. In fact, Pomiès et al. (2007) reported that lactating cows producing $>25 \mathrm{~kg} / \mathrm{d}$ lied down less and displayed increased restlessness when milking frequency was reduced. Similarly, Zobel et al. (2013) described a negative relationship between milk production and lying time after dry-off. The number of lying bouts was not affected by treatment $(P=0.69)$, parity $(P=0.58)$, nor by the interaction between treatment and days relative to dryoff $(P=0.34)$. However, the number of lying bouts was different $(P<0.001)$ depending on the time elapsed since dry-off $(P<0.05)$, with a progressive reduction in the number of lying bouts until d 6 after dry-off (from $7.5 \pm 0.22$ at $\mathrm{d} 1$ to $7.1 \pm 0.22$ bouts/d at $\mathrm{d} 6$ ) followed by a mild recovery thereafter $(7.4 \pm 0.22$ bouts/ min). Contrary to our initial hypothesis, lying bout duration (min/bout) tended $(P=0.09)$ to be shorter in CAB than in CTRL cows and it was unaffected $(P$ $=0.77)$ by parity. However, an interaction $(P<0.001)$ occurred between treatment and days after dry-off. In line with our initial hypothesis, lying bout duration was shorter $(P<0.001)$ during the day following dry-off in CTRL $(94 \pm 3.6 \mathrm{~min} / \mathrm{d})$ than in CAB cows (109 $\pm 3.8 \mathrm{~min}$ (bout), but then, as it occurred with daily lying time, it increased to similar or even greater values than those recorded for $\mathrm{CAB}$ cows on d 4 after dry-off and remained similar thereafter. The shorter lying bout duration in CTRL compared with CAB cows the day following dry-off was probably a reflection of increased discomfort in CTRL than in CAB cows as indicated by the greater udder engorgement. Also, the shorter lying bout duration in CTRL than in CAB cows was probably responsible, in part, for the lower total lying time of CTRL compared with CAB cows the day after drying.

We concluded that cabergoline effectively blocks PRL secretion and it has relatively long-lasting effects $(\sim 15 \mathrm{~d})$ on serum PRL concentrations, causing a reduction in udder engorgement during the first day after dry-off, a reduction in milk leakage during the first 2 $\mathrm{d}$ after dry-off, and an increase in lying time of about additional $90 \mathrm{~min} / \mathrm{d}$ during the first day after dry-off compared with placebo. Therefore, cabergoline could be used as management tool to facilitate the dry-off procedure in dairy cows.

\section{ACKNOWLEDGMENTS}

The authors are grateful to Ceva Santé Animale (Libourne, France) for providing partial funding to conduct this study. Also, the collaboration of Paco Ahedo and Juan Carlos Castro (both from La Travesía, Cortes, Spain) is also acknowledged.

\section{REFERENCES}

British Standards Institution (BSI). 1975. Precision of Test Methods. 1: Guide for the Determination and Reproducibility for a Standard Test Method. BS 597, Part 1. British Standards Institution, London, UK.

Eberhart, R. J. 1986. Management of dry cows to reduce mastitis. J. Dairy Sci. 69:1721-1732.

European Medicines Agency. 2014. European public maximum residues levels assessment report: Cabergoline (bovine). Accessed Aug. 5, 2015. http://www.ema.europa.eu/docs/en_GB/document_library/Maximum_Residue_Limits_-_Report/2014/08/ WC500171572.pdf. 
Ferrari, C., C. Barbieri, R. Caldara, M. Mucci, F. Codecasa, A. Paracchi, C. Romano, M. Boghen, and A. Dubini. 1986. Long-lasting prolactin-lowering effect of cabergoline, a new dopamine agonist, in hyperprolactinemic patients. J. Clin. Endocrinol. Metab. 63:941-945.

Kasum, M., H. Vrčić, P. Stanić, D. Ježek, S. Orešković, L. BeketićOrešković, and M. Pekez. 2014. Dopamine agonists in prevention of ovarian hyperstimulation syndrome. Gynecol. Endocrinol. 30:845-849.

Klaas, I. C., C. Enevoldsen, A. K. Ersbøll, and U. Tölle. 2005. Cowrelated risk factors for milk leakage. J. Dairy Sci. 88:128-136.

Lacasse, P., V. Lollivier, R. M. Bruckmaier, Y. R. Boisclair, G. F. Wagner, and M. Boutinaud. 2011. Effect of the prolactin-release inhibitor quinagolide on lactating dairy cows. J. Dairy Sci 94:1302-1309.

Ledgerwood, D. N., C. Winckler, and C. B. Tucker. 2010. Evaluation of data loggers, sampling intervals, and editing techniques for measuring the lying behavior of dairy cattle. J. Dairy Sci. 93:5129-5139.

Leitner, G., S. Jacoby, E. Maltz, and N. Silanikove. 2007. Casein hydrolyzate intramammary treatment improves the comfort behavior of cows induced into dry-off. Livest. Sci. 110:292-297.

Mattei, A. M., C. Ferrari, P. Baroldi, V. Cavioni, A. Paracchi, C. Galparoli, C. Romano, D. Spellechhia, G. Gerevini, and P. G. Crosignani. 1988. Prolactin-lowering effect of acute and once weekly repetitive oral administration of cabergoline at two dose levels in hyperprolactinemic patients. J. Clin. Endocrinol. Metab. 66:193198.

O'Driscoll, K., D. Gleeson, B. O'Brien, and L. Boyle. 2011. Does omission of a regular milking event affect cow comfort? Livest. Sci 138:132-143
Ollier, S., X. Zhao, and P. Lacasse. 2013. Effect of prolactin-release inhibition on milk production and mammary gland involution at drying-off in cows. J. Dairy Sci. 96:335-343

Ollier, S., X. Zhao, and P. Lacasse. 2014. Effects of feed restriction and prolactin-release inhibition at drying off on metabolism and mammary gland involution in cows. J. Dairy Sci. 97:4942-4954.

Österman, S., and I. Redbo. 2001. Effects of milking frequency on lying down and getting up behaviour in dairy cows. Appl. Anim. Behav. Sci. 70:167-176.

Pomiès, D., B. Martin, Y. Chiliard, P. Pradel, and B. Rémond. 2007. Once-a-day milking of Holstein and Montbéliarde cows for 7 weeks in mid-lactation. Animal 1:1497-1505.

Ponchon, B., P. Lacasse, N. Silanikove, S. Ollier, and X. Zhao. 2014 Effects of intramammary infusions of casein hydrolysate, ethylene glycol-bis( $\beta$-aminoethyl ether)-N,N, $\mathrm{N}^{\prime}, \mathrm{N}^{\prime}$-tetraacetic acid, and lactose at drying-off on mammary gland involution. J. Dairy Sci. 97:779-788.

Rajala-Schultz, P. J., J. S. Hogan, and K. L. Smith. 2005. Association between milk yield at dry-off and probability of intramammary infections at calving. J. Dairy Sci. 88:577-579.

Romagnoli, S., C. Milani, S. Perin, R. Ballabio, C. Stelletta, A. Mollo, and D. Gelli. 2009. Effect of an injectable cabergoline formulation on serum prolactin (PRL) and milk secretion in early postpartum beagle bitches. Reprod. Domest. Anim. 44:148-151.

Tucker, C. B., S. J. Lacy-Hulbert, and J. R. Webster. 2009. Effect of milking frequency and feeding level before and after dry off on dairy cattle behavior and udder characteristics. J. Dairy Sci. 92:3194-3203.

Zobel, G., K. Leslie, D. M. Weary, and M. A. G. von Keyserlingk. 2013. Gradual cessation of milking reduces milk leakage and motivation to be milked in dairy cows at dry-off. J. Dairy Sci. 96:5064-5071. 